\title{
The Implementation of Diversity Values In Social Studies Through Critical Dialogue Method Betweens Students and Their Parents
}

\author{
Lestari Kurniawati \\ SMP Negeri 1 Rangkasbitung \\ lestari.kurniawati@rocketmail.com
}

\author{
Article History \\ accepted 1/09/2020
}

approved 4/10/2020

published 1/12/2020

\begin{abstract}
The formulation of the problem in the research is how to instill the values of diversity in the historical material of the fall of the New Order and how the method of critical dialogue in learning activities at home runs effectively. The methodology in this research uses a qualitative approach, with a qualitative descriptive method. The research findings: 1). The process of cultivating the values of diversity is formed through critical dialogue between students and parents. In the dialogue, several problems were revealed, especially the tragedy of ethnic, religious, and cultural issues which then triggered many negative perspectives towards certain ethnicities. 2). Critical dialogue runs effectively, marked by creating student attention (Attention) to parents 'explanations, creating satisfaction (Satisfaction), students feeling visualization (Visualization) of evidence explained by parents and students feel their parents' explanation is important information which is need (Need) in understanding the material. Bringing action (Action) for students in appreciating differences by writing various narratives of diversity that they have encountered. The conclusion of the study shows that diversity values can be implanted in the historical material of the Fall of the New Order and the method of dialogue between parents of students is effective in instilling the values of diversity.
\end{abstract}

Keywords: Diversity values, fall of the new order, critical dialogue methods

\begin{abstract}
Abstrak
Perumusan masalah dalam penelitian ini bagaimana menanamkan nilai-nilai kebhinekaan pada materi sejarah kejatuhan Orde Baru dan bagaimana metode dialog kritis dalam kegiatan pembelajaran di rumah berjalan dengan efektif. Metodologi dalam penelitian menggunakan pendekatan kualitatif, dengan metode deskriptif kualitatif. Hasil temuan penelitian: 1). Proses penanaman nilai-nilai kebhinekaan, terbentuk melalui dialog kritis antara siswa dan orang tua. Dalam dialog terungkap beberapa permasalahan, terutama tragedi permasalahan etnis, agama, budaya yang kemudian memicu banyak perspektif negatif terhadap etnis tertentu; 2). Dialog kritis berjalan efektif, ditandai dengan terciptanya perhatian siswa (Attention) terhadap penjelasan orang tua, terciptanya kepuasan (Satisfaction), siswa merasakan visualisasi (Visualisation) terhadap bukti-bukti yang dijelaskan oleh orang tua dan siswa merasa penjelasan orang tuanya merupakan informasi penting yang merupakan kebutuhan (Need) dalam memahami materi. Memunculkan tindakan (Action) bagi siswa dalam menghargai perbedaan dengan menuliskan beragam narasi kebhinekaan yang pernah mereka temui. Simpulan penelitian menunjukkan bahwa nilai-nilai kebihinekaan dapat ditanamkan pada materi sejarah Kejatuhan Orde Baru dan metode dialog antara Orang Tua siswa efektif dalam menanamkan nilai-nilai kebhinekaan.
\end{abstract}

Kata Kunci: nilai-nilai kebhinekaan, kejatuhan orde baru, metode dialog kritis

Social, Humanities, and Education Studies (SHEs): Conference Series p-ISSN 2620-9284 https://jurnal.uns.ac.id/shes

e-ISSN 2620-9292 


\section{PENDAHULUAN}

Masalah yang dialami negara yang memiliki beragam corak kebudayaan, tidak jauh dari masalah kebhinekaan itu sendiri, seperti memiliki local wisdom, heterogenitas budaya, pancaragam agama, keragaman adat istiadat, suku bangsa dan lain sebagainya. Sejak berdirinya bangsa Indonesia 1945, hingga zaman reformasi masalah SARA (Suku, Agama, Ras dan Antargolongan) senantiasa mewarnai perjalanan bangsa ini. Bahkan ketika bangsa tengah di uji wabah pandemi Covid-19, pada saat siswa melakukan Aktivitas Belajar Dari Rumah (BDR), masih saja ada kasus tawuran antarpelajar, selanjutnya di tengah pemeriksaan Covid-19 pula muncul ujaran kebencian dan berita bohong yang dialamatkan pada Seminari Bethel. (Amali, 2020).

Dimanakah peran lembaga pendidikan dan keluarga ketika isu SARA tak pernah padam? Inilah yang kemudian menjadi autokritik penulis sebagai guru IPS. Selama ini yang terjadi adalah adanya kesan 'masing-masing' antara guru dan orang tua siswa dalam mendidik siswa (bagi guru) dan anak (bagi orangtua). Hal ini sangat terasa di tengah PJJ (Pembelajaran Jarak Jauh), ternyata revitalisasi jalinan hubungan guru dan orang tua harus berkualitas. Bagaimana pendidikan orang tua di rumah dalam menanggapi masalah SARA dan bagaimana peran guru di sekolah, bersinergi dalam rangka memutus rantai antitoleransi dan alergi terhadap perbedaan budaya? Bagaimana kegiatan belajar di rumah, efektif dalam melibatkan peran orang tua untuk mendampingi belajar anaknya di rumah?

Hasil survei pendapat yang penulis sebar lewat google form, menyatakan bahwa dari 93 sampel siswa, diperoleh fakta selama BDR sekitar 69,9\% siswa belajar sendiri, $10,8 \%$ belajar dengan ditemani kakaknya, 18,3\% didampingi oleh ibunya, dan hanya $1,1 \%$ ditemani oleh ayah. Sedangkan orang tua mereka saat ini berada pada kisaran usia 30-40 tahun (32,3\%), usia 41-50 tahun (53,8\%), usia 51-60 tahun (12,9\%), dan usia di atas 60 tahun sekitar $1 \%$.

Kendala yang mereka temui selama BDR didominasi oleh tidak adanya teman dialog untuk bertanya kesulitan belajar sebanyak $46,7 \%$, mengalami kesusahan sinyal internet $17,4 \%$, dan sebanyak $35,9 \%$ adalah persoalan kuota internet. Para siswa berharap selama BDR memiliki teman untuk diskusi (52,7\%), pemenuhan kuota internet $(27,5 \%)$, pendampingan orang tua $(12,1 \%)$, sisanya minta didampingi oleh guru sebanyak $7,7 \%$. Hal ini mempertajam permasalahan esensial mengenai pentingnya teman dialog sebanyak $63,4 \%$, sedangkan $18,3 \%$ menganggap teman dialog tidak begitu penting dan $17,2 \%$ beranggapan sangat penting.

Pendidikan keluarga merupakan bagian dari pendidikan utama dan pertama, sebelum siswa di lepas ke sekolah. Namun, peran orang tua sebagaimana tertuang dalam Undang-undang Sistem Pendidikan Nasional tahun 2003, pasal 7 ayat 1 dan 2 mengalami eliminasi. Misalnya, pada ayat 1 yang berbunyi orang tua berhak berperan serta dalam memilih satuan pendidikan dan memperoleh informasi mengenai perkembangan anaknya, dapat diasumsikan bahwa seolah-olah tanggung jawab utama sudah tergantikan oleh pemerintah. Karena peran orang tua hanya memilihkan sekolah dan menanyakan perkembangan anaknya, ada lepas tangan dari peran utama dan pertama orang tua di sana. Kemudian pada ayat 2, berbunyi "orang tua dari anak usia wajib belajar, berkewajiban memberikan pendidikan dasar kepada anaknya". Namun ayat kedua ini juga tidak ada penjelasan lebih lanjut, seolah peran dan tanggung jawab utama dan pertama hanya sampai tingkat dasar. Bagaimana pendampingan orang tua pada jenjang sekolah berikutnya?

Inilah momentum yang tepat, bagaimana BDR merevitalisasi pendampingan orang tua di rumah selama anaknya belajar. Sedangkan peran guru, bagaimana caranya supaya orang tua dapat terlibat secara langsung pada triangle collaborator in education (segitiga antara orang tua siswa, siswa, dan guru). Bagaimanapun, pendidikan di rumah adalah pintu gerbang implementasi nilai-nilai kebhinekaan. Sehingga, konflik yang 
menyangkut unsur suku, agama, ras dan antargolongan tidak lagi menjadi rantai yang tidak bisa diputus. Guru, orangua siswa dan siswa, harus mengambil alih dialektika kebhinekaan Indonesia, sehingga belajar menghargai, memahami dan bekerja sama dimulai dari lingkungan terkecil, yakni keluarga, sekolah baru kemudian masyarakat luas.

\section{METODE}

Pendekatan dalam penelitian ini menggunakan kualitatif, metode yang diambil adalah deskriptif kualitatif. Metode deskriptif kualitatif atau dalam pendekatan kualitatif disebut dengan Narrative Research. "Narrative, might be the term assigned to any text or discourse, or. It might be text used within the context of a mode of inquiry in qualitative research, with specific focus on the stories told by individuals". (Cresswell, 2007)

Adapun pengertian naratif adalah istilah yang ditetapkan untuk teks atau wacana apa pun, atau mungkin teks yang digunakan dalam konteks model penyelidikan dalam penelitian kualitatif, yang fokus khusus pada cerita yang diceritakan oleh individu. Penelitian dilakukan di SMPN 1 Rangkasbitung dengan subyek penelitian adalah siswa/I kelas 9. Waktu penelitian dilaksanakan pada bulan April 2019. Implementasi nilai-nilai kebhinekaan dilakukan dalam kegiatan pembelajaran dengan menggunakan metode Project based learning. Metode Project based learning secara teoritis memiliki argumentasi dapat diterapkan dalam rangka internalisasi dan implementasi nilai. (Nurohman, 2013) Implementasi nilai yang di maksud adalah nilai-nilai kebhinekaan pada materi IPS Kelas 9 Semester 2, yakni menyajikan hasil analisis kronologi, perubahan dan kesinambungan ruang (geografis, politik, ekonomi, pendidikan, sosial, budaya) dari awal kemerdekaan sampai awal reformasi. Materi yang di pilih adalah Masa Orde Baru hingga Orde Reformasi, terkait isu SARA.

Sintaks yang digunakan selama pembelajaran menggunakan project based learning dari The George Lucas Educational Foundation, (Foundation, The George Lucas Educational, 2007) sebagai berikut:

1. Start with the Essential Question.

Pada permulaan pembelajaran, guru memberikan stimulus kepada siswa untuk menemukan pertanyaan esensial yang berhubungan dengan tema-tema pembelajaran yang akan dilaksanakan. Pertanyaan esesial diharapkan muncul oleh siswa setelah memahami konteks pembelajaran dengan realitas di lingkungan tempat tinggal siswa.

2. Design a Plan for the Project.

Pada tahap ini, guru memberikan beraneka ragam tema untuk ditentukan tema pilihan siswa dan orang tua. Terlebih dahulu, guru membuat dua group WAG siswa dan Orang Tua. Pada tahap ini, guru, siswa dan orang tua mendiskusikan PjBL yang akan dilaksanakan terkait materi yang dipelajari siswa. Kemudian, siswa di tugaskan untuk mulai menyusun daftar pertanyaan yang akan dijadikan pedoman wawancara. Pedoman wawancara digunakan saat melakukan interview bersama orang tua di rumah masing-masing.

3. Create a Schedule. Pada tahapan ini, guru membuat jadwal penelitian yang hendak dilakukan oleh siswa dan orang tuanya. Jadwal dibuat fleksibel dan tidak terlalu ketat. Disini siswa dan orang tua diberikan tenggat waktu yang leluasa dalam berkolaborasi sebaik mungkin dalam mendalami sebuah tema yang telah disepakati bersama.

4. Monitor the Students and The Progress the Project. Untuk memastikan apakah siswa dan orang tua bersama-sama melakukan kolaborasi dalam proyek ini, siswa diminta merekam hasil wawancaranya kepada orang tua dalam bentuk video serta menyerahkan laporan secara tertulis. Guru juga turut terlibat dalam mengoreksi setiap tahapan yang belum sesuai dengan target pencapaian. 
5. Access the Outcome. Guru melakukan evaluasi dengan memeriksa hasil laporan video dan laporan tertulis siswa, dengan harapan bahwa PjBL memberikan makna dalam aktivitas belajar di rumah. Hasil implementasi ini dapat dituangkan siswa melalui argumentasi terkait "isu SARA dan perbedaan" secara tertulis, kemudian penilaian jurnal sikap yang dilakukan oleh guru.

6. Evaluate the Experiment. Tahapan akhir dari proses $\mathrm{PjBL}$ adalah melakukan refleksi antara orang tua, siswa dan guru dengan meminta pandangannya atas $\mathrm{PjBL}$ yang dilakukan, secara lisan di kemukalkan oleh orang tua dan siswa dalam waktu bersamaan.

\section{TEORI}

\section{NILAI-NILAI KEBHINEKAAN}

Kebangsaan merupakan proses dialektika dari nilai-nilai kebhinekaan yang kemudian disatukan dalam internalisasi nilai dan kepribadian bangsa. Proses internalisasi nilai akan meningkat bila sejalan dengan cita-cita dan tujuan bangsa Indonesia yang dibantu oleh cultural-local value (nilai kultural-lokal) dari setiap daerah di Indonesia. Bangsa Indonesia yang terkenal akan multikultural menjadi modal dasar dalam pembentukan karakter dan kerpibadian bangsa. Multikulturalisme adalah konsep pembudayaan yang dapat diciptakan melalui proses pendidikan (Tilaar, 2012). Multikultural tidak terlepas dengan proses inte rnalisasi nilai dan pendidikan dalam berbagai aspek dimensi. Menurut Banks, setidaknya ada lima dimensi pendidikan multikultural yang dapat membantu guru dalam mengimplementasikan nilai-nilai kebhinekaan dalam kegiatan pembelajaran, diantaranya: Dimensi integrasi isi atau materi (content integration), Dimensi konstruksi pengetahuan (knowledge construction), Dimensi Pengurangan prasangka (prejudice reduction), Dimensi pendidikan yang sama/adil (equitable pedagogy), dan Dimensi pemberdayaan budaya sekolah dan struktur sosial (empowering school culture and social structure). (Ambarudin, 2016)

Lebih lanjut, Nurgiyantoro dan Tobroni, menyatakan dalam multikultural ada 7 nilai yang mencerminkan kebhinekaan, yaitu:

1. Solidaritas dan persaudaraan

2. Kesetaraan gender

3. Nilai kekeluargaan

4. Penghormatan terhadap tata sosial

5. Merasa cukup dalam hidup

6. Berpandangan terbuka

7. Berbagi dan kontrol kekuasaan (Nurgiyantoro, 2010)

Kebhinekaan memungkinkan kelompok budaya yang berbeda untuk mempertahankan budaya mereka yang unik sambil berpartisipasi secara setara dalam budaya dominan. Secara tegas, hal ini juga dikemukakan oleh Lewis bahwa keberagaman memungkinkan individu untuk memilih keanggotaan dalam kelompok budaya dan sosial yang paling sesuai dengan identitas mereka tanpa takut dikucilkan atau diisolasi dari kelompok asli atau kelompok baru mereka. (Donna M.Gollnick, 2013). Nampak dalam pernyataan Lewis bahwa kebhinekaan atau multikulturalisme sebagai individu dan kelompok yang membebaskan diri dari ekstrem identitas homogenisasi dan kolektif, dicirikan dengan sikap yang lebih terbuka dan menghormati perbedaan budaya, baik di dalam maupun di luar batas negara.

\section{KEJATUHAN ORDE BARU}

Sentimen lokal dan munculnya konflik horizontal awal reformasi umumnya bernuansa etnis dan agama. Daerah konflik meluas tidak hanya di Jawa sebagai pusat pemerintahan, namun bergaung juga di Ambon, Kalimantan Barat, munculnyaberagam gerakan separatisme. Erupsi konflik kekerasan-pada awal kejatuhan rezim Soehartomenyebar hampir di seluruh wilayah Indonesia. Kerusuhan marak terjadi dibeberapa 
kota besar di Indonesia, seperti Jakarta. Serangkaian kekerasan komunal berkepanjangan yang bernuansa etnis dan agama muncul di Kalimantan, Sulawesi, dan Maluku. Di samping itu, aksi-aksi kekerasan atas nama pro kemerdekaan di Aceh dan Papua mengalami peningkatan tajam, terlebih ketika negara merespon dengan operasi militer yang masif. Gejolak politik keamanan di provinsi Timor Timur juga menggeliat dan kelompok pro kemerdekaan semakin progresif menuntut pemisahan diri dari Indonesia.

Maraknya konflik kekerasan merupakan resiko fase awal pemerintahan menuju transisi demokrasi, terlebih ketika para elite terancam oleh perubahan politik (Snyder, 2000). Jacques Bertrand (Bertrand, 2004) menganggap bahwa periode awal transisi di Indonesia adalah titik kritis (critical junctures). Momen perubahan dari rezim otoriter menjadi demokratis sangat rentan dengan beragam gejolak. Terlebih dengan bangunan institusi demokrasi yang masih rapuh, konflik kekerasan di tengah masyarakat menjadi fenomena yang tidak terelakan. Di sisi lain, kelompok-kelompok masyarakat memanfaatkan posisi negara yang lemah dengan melakukan berbagai upaya kekerasan terhadap kelompok lain atas nama marjinalisasi selama rezim Orde Baru (Klinken, 2007). Ini yang disebutkan oleh Francis Stewart (Stewart, 2002) sebagai faktor

ketidaksetaraan horizontal (horizontal inequality). Pada awal transisi demokrasi di Indonesia kasus-kasus kekerasan, khususnya konflik horizontal, turut dipengaruhi oleh adanya hubungan yang tidak setara antara kelompok-kelompok di dalam masyarakat

\section{DIALOG KRITIS}

Dialogisme menurut Freire membutuhkan pendidik yang memiliki kematangan jiwa atau semangat berpetualang guna menstimulus siswa mencari tahu dan merekonstruksi sendiri pemahamannya. Sesederhana apapun pertanyaan yang terlontar dari siswa, tetap membutuhkan keseriusan dalam memberikan jawabanjawaban. Asumsi yang harus dimiliki pendidik adalah bahwa dalam suasana berdialog, orang yang bertanya mengetahui sebab mengapa ia bertanya. Keyakinan bahwa siswa tidak mengajukan pertanyaan, hanya untuk bertanya atau supaya nampak belajar di mata gurunya dan orang yang mendengar pertanyaannya. (Freire, 2001)

Dialog membentuk hubungan epistimologis. Objek yang hendak diketahui di satu tempat menghubungkan dua subjek kognitif, yang mengarahkan untuk bersama-sama merefleksi objek. Dialog adalah saling merekatkan antara guru, siswa dan orang tua melalui "tindakan mengetahui" (act of knowing) dan "mengetahui ulang" (re-knowning) objek studi secara bersama-sama. Inti dialog harus mengandung refleksi dan aksi, tanpa refleksi, dialog hanya aktivisme, sedangkan tanpa aksi, dialog hanya verbalisme. Hanya melalui praksis, yang merupakan perpaduan antara aksi dan refleksi, kata menjadi benar-benar hidup dan mampu menggerakan hati. (Shor, 2001)

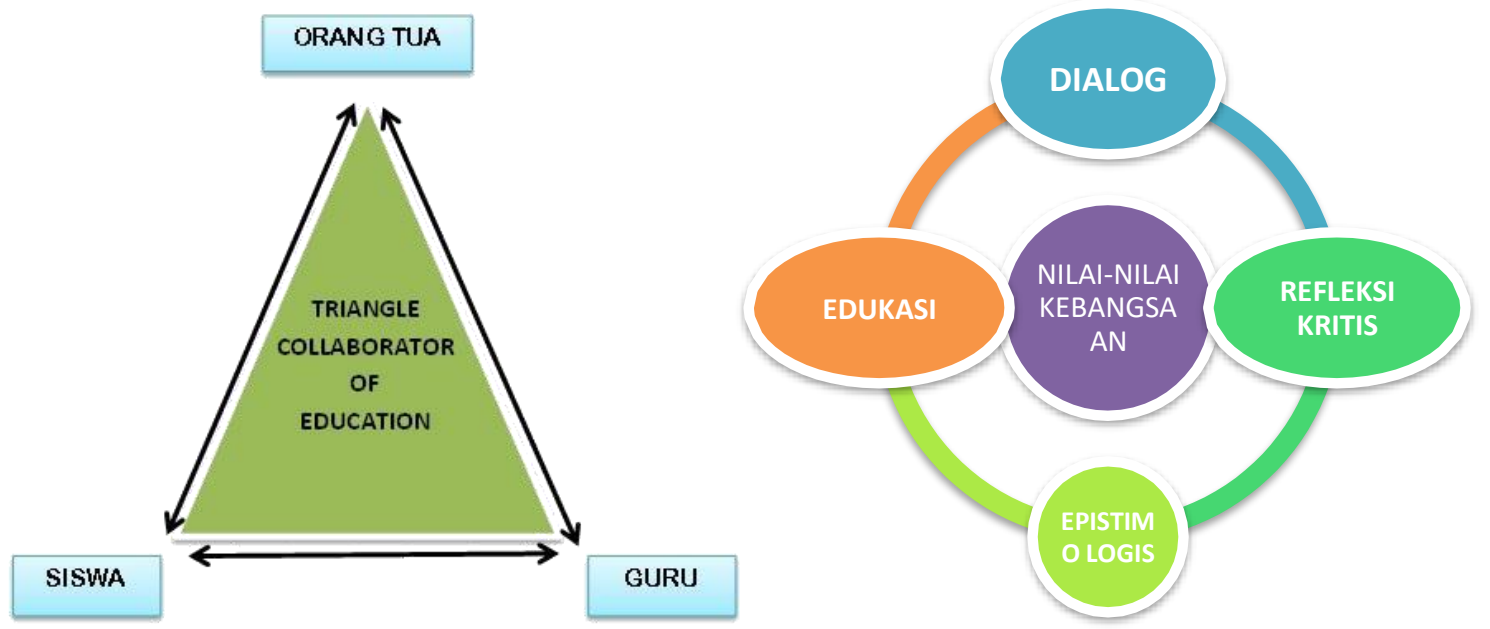

Gambar 1: Triagle Collaborator of Education dan Kerangka Pembelajaran Nilai-nilai Kebangsaan 
Penciptaan suasana kelas yang otoriter, dimana pengetahuan tertinggi hanya milik seorang pendidik, akan mengkerdilkan lahirnya ilmu pengetahuan, karena dialogisme syarat terjadinya epistemologis. Selain itu, antidialog yang otoriter merampas hak manusia untuk menemukan pengetahuan, selain bertentangan dengan demokrasi dan melanggar kodrat manusia sejatinya yang ingin serba tahu. Agar proses pembelajaran sesuai dengan kodrat manusia sebagai makhluk sosial dan berpendidikan maka diperlukan metode yang efektif antara collaborator of education (guru, siswa dan orang tua) membangun kerangka dialogis kritis dan terbuka, sehingga proses penemuan dan transfer pengetahuan berjalan sesuai kodratnya.

\section{HASIL DAN PEMBAHASAN}

Pada penelitian kali ini, siswa dan orang tua sebagai informan melakukan dialog mendalam membicarakan pengalaman dengan yang berhubungan dengan isu konflik yang terkait SARA dan kaitan dengan materi Kejatuhan Orde Baru. Dialog terjadi ketika siswa menanyakan draf pertanyaan yang sudah dibuat siswa sebelumnya. Kemudian siswa merekam hasil dialog dan wawancara dengan informan dalam bentuk video dan laporan tertulis. Setelah siswa melakukan dialog dan wawancara dengan informan/orang tua dan mengirimkan video dan laporan tertulis mengenai hasil dialog dengan informan, peneliti melakukan analisis data melalui tahapan reduksi data penelitian (memilah, mengelompokkan dan menyederhanakan hasil temuan beserta tema dan pola), menyajikan data (membuat matrik/ tabel isu-konflik dan matriks/tabel efektivitas dialog kritis siswa dan informan/orang tua) dan terakhir melakukan verifikasi (penarikan kesimpulan).

\section{Tahapan Reduksi Data}

Berdasarkan hasil reduksi data penelitian, didapatkan tema-tema yang saling terkait pada hasil dialog siswa dengan informan, antara lain: Tema 1: isu/konflik yang berkembang, Tema 2: subjek yang terlibat dalam konflik, Tema 3: Inti permasalahan mengain isu/konflik yang terjadi, Tema 4: Solusi dan Tema 5: Internalisasi Nilai. Selanjutnya peneliti melakukan proses reduksi dalam memilah dan menyederhanakan proses dialog kritis siswa dan informan dengan menemukan pola perilaku yang unik. Adapun pola tersebut adalah: Pola 1: Perhatian Siswa terhadap Dialog (Attention), Pola 2: Kepuasan yang dialami oleh siswa setelah melakukan dialog (Satisfaction), Pola 3: Bentuk visualisasi siswa setelah melakukan dialog (Visualisation), Pola 4: Fakta dan informasi yang diberikan oleh Informan penelitian dianggap oleh siswa sebagai kebutuhan akan informasi yang penting (Need) dan Pola 5: Setelah siswa melalukan dialog dan meresapi nilai dan informasi yang diberikan oleh informan, maka diperlukan tindakan nyata dalam mengimplementasikan nilai/informasi tersebut (Action).

\section{Tahapan Penyajian Data}

Berdasarkan temuan penelitian yang dilakukan oleh peneliti, didapatkan sejumlah data dan fakta bahwa banyak konflik yang terjadi pada masa Kejatuhan Orde Baru, juga terlihat pada lingkungan tempat tinggal siswa dan orang tua pada skala dan prioritas yang lebih kecil cakupannya. Para siswa menjelaskan bentuk isu/konflik yang berkembang di lingkungan tempat tinggalnya atau yang pernah dirasakan oleh orang tua. Penjalasan hasil dialog siswa dengan informan/orang tua mampu memberikan informasi yang beragam dan nilai-nilai yang positif terhadap siswa. Untuk itu, peneliti merangkumnya dalam bentuk tabel isu/konflik. 
Tabel 1. Isu/Konflik

\begin{tabular}{|c|c|c|c|c|c|}
\hline $\begin{array}{l}\text { KELOMPOK } \\
\text { PENUGASAN }\end{array}$ & ISU/KONFLIK & $\begin{array}{l}\text { SUBJEK } \\
\text { YANG } \\
\text { TERLIBAT }\end{array}$ & $\begin{array}{c}\text { INTI } \\
\text { PERMASALAHAN }\end{array}$ & $\begin{array}{l}\text { SOLUSI } \\
\text { KONKRIT }\end{array}$ & $\begin{array}{c}\text { INTERNALIASASI } \\
\text { NILAI }\end{array}$ \\
\hline
\end{tabular}

\begin{tabular}{|c|c|c|c|c|c|}
\hline$\underset{1}{\text { KELOMPOK }}$ & $\begin{array}{l}\text { Konflik } \\
\text { Pengembang } \\
\text { Pasar } \\
\text { Rangkasbitung } \\
\text { dan para } \\
\text { pedagang }\end{array}$ & $\begin{array}{l}\text { Pedagang dan } \\
\text { pengelola } \\
\text { pasar } \\
\text { Rangkasbitung, } \\
\text { Kabupaten } \\
\text { Lebak-Banten }\end{array}$ & $\begin{array}{l}\text { Pembongkaran } \\
\text { paksa kios } \\
\text { pedagang }\end{array}$ & $\begin{array}{l}\text { Renegosiasi } \\
\text { ulang antara } \\
\text { pengembang } \\
\text { pasar dan } \\
\text { pedagang }\end{array}$ & $\begin{array}{l}\text { Dialogis antar } \\
\text { pelaku ekonomi di } \\
\text { Pasar } \\
\text { Rangkasbitung } \\
\text { dengan Pemda }\end{array}$ \\
\hline
\end{tabular}

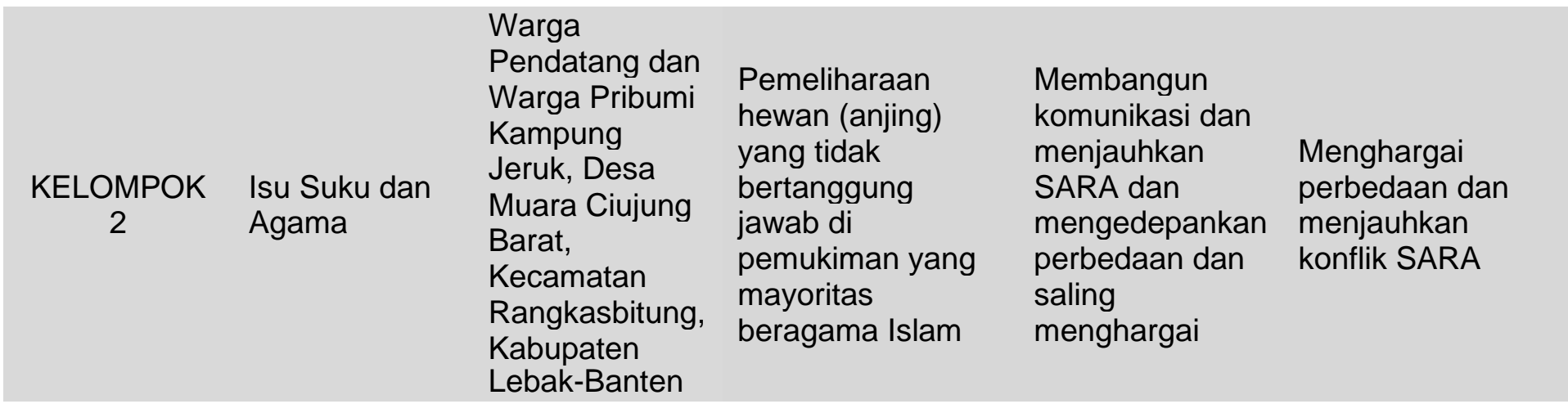

\begin{tabular}{|c|c|c|c|c|c|}
\hline $\begin{array}{c}\text { KELOMPOK } \\
3\end{array}$ & $\begin{array}{l}\text { Isu } \\
\text { Penyimpangan } \\
\text { Ajaran Agama }\end{array}$ & $\begin{array}{l}\text { Warga dengan } \\
\text { anggota } \\
\text { kelompok } \\
\text { agama tertentu } \\
\text { di Kecamatan } \\
\text { Lebak Gedong, } \\
\text { Kabupaten } \\
\text { Lebak-Banten }\end{array}$ & $\begin{array}{l}\text { Penyimpangan } \\
\text { ajaran Agama } \\
\text { Islam oleh } \\
\text { kelompok aliran } \\
\text { sesat }\end{array}$ & $\begin{array}{l}\text { Dialog dan } \\
\text { musyawarah } \\
\text { serta } \\
\text { pencerahan dari } \\
\text { Muspika dan } \\
\text { tokoh agama } \\
\text { setempat }\end{array}$ & $\begin{array}{l}\text { Musyawarah antar } \\
\text { sesama golongan } \\
\text { masyarakat }\end{array}$ \\
\hline
\end{tabular}

\begin{tabular}{|c|c|c|c|c|c|}
\hline$\underset{4}{\text { KELOMPOK }}$ & $\begin{array}{l}\text { Konflik } \\
\text { Tanjung Priok }\end{array}$ & $\begin{array}{l}\text { Warga dengan } \\
\text { oknum militer } \\
\text { (pernah } \\
\text { dirasakan oleh } \\
\text { salah satu } \\
\text { orang tua siswa } \\
\text { SMPN } 1 \\
\text { Rangkasbitung) }\end{array}$ & $\begin{array}{l}\text { Diduga karena } \\
\text { adanya provokasi, } \\
\text { serta adanya isu } \\
\text { SARA dan } \\
\text { Aroganisme pihak } \\
\text { pemerintah yang } \\
\text { menimbulkan } \\
\text { Konflik ini terjadi }\end{array}$ & $\begin{array}{l}\text { Melalui Komnas } \\
\text { HAM dan } \\
\text { pengadilan }\end{array}$ & $\begin{array}{l}\text { Proses } \\
\text { mengedukasi } \\
\text { masyarakat agar } \\
\text { tidak mudah } \\
\text { terprovokasi dan } \\
\text { menjauhkan } \\
\text { konflik SARA }\end{array}$ \\
\hline $\begin{array}{c}\text { KELOMPOK } \\
5\end{array}$ & $\begin{array}{l}\text { Konflik } \\
\text { perkelahian }\end{array}$ & $\begin{array}{l}\text { Tawuran antar } \\
\text { pelajar yang } \\
\text { melibatkan } \\
\text { warga sekitar } \\
\text { (Kecamatan } \\
\text { Rangkasbitung, } \\
\text { Kabupaten } \\
\text { Lebak-Banten) }\end{array}$ & $\begin{array}{l}\text { Aksi anarkisme } \\
\text { dan bullying antar } \\
\text { pelajar dan warga } \\
\text { setempat }\end{array}$ & $\begin{array}{l}\text { Proses } \\
\text { pengamanan } \\
\text { oleh Polisi }\end{array}$ & $\begin{array}{l}\text { Menjauhkan } \\
\text { anarki dan hal } \\
\text { yang bersifat } \\
\text { destruktif }\end{array}$ \\
\hline
\end{tabular}


Selanjutnya peneliti menyajikan data berupa matrik/tabel mengenai proses dialog kritis siswa dan informan berdasarkan Pola 1: Perhatian Siswa terhadap Dialog (Attention), Pola 2: Kepuasan yang dialami oleh siswa setelah melakukan dialog (Satisfaction), Pola 3: Bentuk visualisasi siswa setelah melakukan dialog (Visualisation), Pola 4: Kebutuhan akan informasi yang penting (Need) dan Pola 5: tindakan nyata dalam mengimplementasikan nilai/informasi tersebut (Action). Adapun matrik/tabel proses dialog kritis siswa dan informan, sebagai berikut:

Tabel 2. Proses Dialog Kritis Siswa dan Informan

\begin{tabular}{cl}
$\begin{array}{c}\text { KELOMPOK } \\
\text { PENUGASAN }\end{array}$ & $\begin{array}{c}\text { PERHATIAN } \\
\text { (ATTENTION) }\end{array}$ \\
\hline & Setiap anggota \\
kelompok \\
merasakan \\
bahwa dialog \\
yang terjadi \\
dengan \\
informan \\
merupakan hal
\end{tabular}

KELOMPOK yang baru dan 1

KELOMPOK 2
Bentuk visualisasi yang dialami oleh kelompok berupa berita online di internet dan penuturan langsung dari informan masyarakat Kota Rangkasbitung, khususnya di daerah Pasar Rangkasbitung

Kelompok merasakan intensitas konflik antara suku pendatang dengan suku pribumi menjadi bagian penting dan sering kali terjadi di lingkungan tempat tinggal mereka

\section{VISUALISASI} (VISUALISATIOM)
KEPUASAN (NEED)

\section{(SATISFACTION)}

TINDAKAN (ACTION)
Kelompok memberikan saran kepada pihak pengembang agar lebih bersikap persuasif dalam bertindak dan kepada Pemda Lebak agar membuat aturan yang jelas bagi kedua belah pihak
Dialog yang

Proses visualiasi yang dialami oleh kelompok hanya berdasarkan penuturan informan dan membayangkan konflik ini bisa saja terjadi di lingkungan sekitar

\section{Kelompok} menganggap hal ini penting untuk diminimalisir agar bibit konflik di lingkungan pemukiman warga menjadi kondusif dilakukan dengan informan memberikan informasi penting bagi kelompok agar mengedepankan komunikasi dan menghargai perbedaan di lingkungan masyarakat
Kelompok memberikan masukan agar perlu adanya sosialisasi tingkat RT agar konflik seperti ini tidak terulang kembali 
SHEs: Conference Series 3 (2) (2020) 43 - 59

\begin{tabular}{|c|c|c|c|c|c|}
\hline $\begin{array}{c}\text { KELOMPOK } \\
3\end{array}$ & $\begin{array}{l}\text { Kelompok } \\
\text { menganggap } \\
\text { isu } \\
\text { penyimpangan } \\
\text { agama menjadi } \\
\text { hal yang } \\
\text { penting dalam } \\
\text { proses } \\
\text { bermasyarakat }\end{array}$ & $\begin{array}{l}\text { Proses visualisasi } \\
\text { yang dialami oleh } \\
\text { kelompok } \\
\text { menganggap isu } \\
\text { penyimpangan } \\
\text { agama berpotensi } \\
\text { besar menjadi } \\
\text { konflik yang lebih } \\
\text { besar lagi bila } \\
\text { tidak ditangani } \\
\text { dengan benar dan } \\
\text { bijak }\end{array}$ & $\begin{array}{l}\text { Konflik } \\
\text { mengenai } \\
\text { penyimpangan } \\
\text { ajaran agama } \\
\text { menjadi hal } \\
\text { yang sensitif } \\
\text { dan wajib } \\
\text { menjadi } \\
\text { tanggung } \\
\text { jawab semua } \\
\text { pihak }\end{array}$ & $\begin{array}{l}\text { Setelah dialog } \\
\text { dilakukan, } \\
\text { kelompok } \\
\text { menyatakan } \\
\text { kepuasan bahwa } \\
\text { penyimpangan } \\
\text { ajaran agama } \\
\text { menjadi hal } \\
\text { berbahaya bagi } \\
\text { proses } \\
\text { keagamaan }\end{array}$ & $\begin{array}{l}\text { Perlu adanya } \\
\text { pengawasan } \\
\text { yang lebih } \\
\text { intesif dalam } \\
\text { hal } \\
\text { keagamaan di } \\
\text { lingkungan } \\
\text { sekitar agar } \\
\text { tidak ada } \\
\text { kasus } \\
\text { penyimpangan } \\
\text { ajaran agama }\end{array}$ \\
\hline $\begin{array}{c}\text { KELOMPOK } \\
4\end{array}$ & $\begin{array}{l}\text { Kelompok } \\
\text { beranggapan } \\
\text { bahwa kasus } \\
\text { Tanjung Priok } \\
\text { merupakan } \\
\text { kasus berskala } \\
\text { besar yang } \\
\text { berhubungan } \\
\text { dengan isu } \\
\text { agama dan } \\
\text { ideologi }\end{array}$ & $\begin{array}{l}\text { Proses visualisasi } \\
\text { yang dialami oleh } \\
\text { kelompok berupa } \\
\text { berita online di } \\
\text { internet dan } \\
\text { penuturan } \\
\text { langsung dari } \\
\text { informan }\end{array}$ & $\begin{array}{l}\text { Kelompok } \\
\text { menjelaskan } \\
\text { bahwa kasus } \\
\text { Tanjung Priok } \\
\text { harus secara } \\
\text { tuntas } \\
\text { diselesaikan } \\
\text { tidak hanya } \\
\text { pada bidang } \\
\text { hukum dan } \\
\text { HAM, tapi juga } \\
\text { pada bidang } \\
\text { sosial dan } \\
\text { agama }\end{array}$ & $\begin{array}{l}\text { Kelompok } \\
\text { merasakan hal } \\
\text { yang begitu } \\
\text { penting dalam } \\
\text { perjalanan } \\
\text { sejarah bangsa } \\
\text { Indonesia masa } \\
\text { Orde Baru, dan } \\
\text { menjadi } \\
\text { pembelajaran } \\
\text { bagi generasi } \\
\text { penerus }\end{array}$ & $\begin{array}{l}\text { Kelompok } \\
\text { beranggapan } \\
\text { harus ada } \\
\text { proses } \\
\text { mengedukasi } \\
\text { masyarakat } \\
\text { agar tidak } \\
\text { mudah } \\
\text { terprovokasi } \\
\text { dan } \\
\text { menjauhkan } \\
\text { konflik SARA }\end{array}$ \\
\hline $\begin{array}{c}\text { KELOMPOK } \\
5\end{array}$ & $\begin{array}{l}\text { Konflik } \\
\text { perkelahian } \\
\text { pelajar } \\
\text { dianggap } \\
\text { konflik yang } \\
\text { sering kali } \\
\text { terjadi dan } \\
\text { berbahaya bagi } \\
\text { generasi muda }\end{array}$ & $\begin{array}{l}\text { Proses visualisasi } \\
\text { yang dialami oleh } \\
\text { kelompok } \\
\text { menganggap } \\
\text { bahwa } \\
\text { perkelahian } \\
\text { pelajar yang } \\
\text { melibatkan warga } \\
\text { mampu } \\
\text { mencoreng nama } \\
\text { baik Kota } \\
\text { Rangkasbitung } \\
\text { sebagai Kota yang } \\
\text { Damai }\end{array}$ & $\begin{array}{l}\text { Kelompok } \\
\text { memberikan } \\
\text { penjelasan } \\
\text { bahwa dalam } \\
\text { meminimalisir } \\
\text { terjadinya } \\
\text { tawuran, perlu } \\
\text { peran serta } \\
\text { orang tua, } \\
\text { sekolah dan } \\
\text { Pemda Kab. } \\
\text { Lebak dalam } \\
\text { mengedukasi } \\
\text { siswa/anak ke } \\
\text { arah aktivitas } \\
\text { yang lebih } \\
\text { produktif dan } \\
\text { positif. }\end{array}$ & $\begin{array}{l}\text { Kelompok melihat } \\
\text { konflik tawuran } \\
\text { menjadi hal yang } \\
\text { bersifat sering } \\
\text { terjadi bila tidak } \\
\text { ada penanganan } \\
\text { yang tepat }\end{array}$ & $\begin{array}{l}\text { Kelompok } \\
\text { mengusulkan } \\
\text { ide agar } \\
\text { sekolah atau } \\
\text { Pemda Kab. } \\
\text { Lebak harus } \\
\text { banyak } \\
\text { menciptakan } \\
\text { kegiatan event } \\
\text { yang lebih } \\
\text { positif } \\
\text { dikalangan } \\
\text { pelajar/siswa. }\end{array}$ \\
\hline
\end{tabular}




\section{SIMPULAN}

Berdasarkan hasil penelitian, maka dapat disimpulkan bahwa proses penanaman nilai-nilai kebhinekaan, dapat terbentuk melalui dialog kritis antara siswa dan orang tua. Dalam dialog terungkap beberapa permasalahan, terutama tragedi permasalahan etnis, agama, budaya yang kemudian memicu banyak perspektif negatif terhadap etnis tertentu. Selanjutnya, dialog kritis dapat berjalan dengan efektif, ditandai dengan terciptanya perhatian siswa (Attention) terhadap penjelasan orang tua, terciptanya kepuasan (Satisfaction), siswa merasakan visualisasi (Visualisation) terhadap bukti-bukti yang dijelaskan oleh orang tua dan siswa merasa penjelasan orang tuanya merupakan informasi penting yang merupakan kebutuhan (Need) dalam memahami materi. Memunculkan tindakan (Action) bagi siswa dalam menghargai perbedaan dengan menuliskan beragam narasi kebhinekaan yang pernah mereka temui.

\section{DAFTAR PUSTAKA}

Amali, Z. 2020. Kronologi Penularan Corona Seminari Bethel \& Mengapa Jadi Isu SARA. Jakarta: Tirto.id.

Ambarudin, R. 2016. Pendidikan Multikultural untuk Membangun Bangsa yang Nasionalis Religius. Civics, Vol.13 No.1, 34-35.

Bertrand, J.2004. Nationalism and Ethnic Conflict in Indonesia. Cambridge: Cambridge University Press.

Cresswell, J. W. 2007. Qualitative Inquiry and Research Design: Choosing The Among Five Approach. California: Sage Publication, Inc.

Donna M.Gollnick, P. C. 2013. Multiculural Education in a Pluralistic Society. United States: Pearson.

Foundation, The George Lucas Educational. (2007, July 10). Instructional Module Project Based Learning. Dipetik September 25, 2020, dari The George Lucas Educational Foundation: http://www.edutopia.org/moduls/PBL/what.pbl.php

Freire, P. 2001. Pedagogi Hati. Yogyakarta: Penerbit Kanisius.

Klinken, G. v. 2007. Communal Violence and Democratization in Indonesia: Small Town Wars. London: Routledge.

Nurgiyantoro, T. d. 2010. Multikulturalisme dalam Cerita Tradisional Yogyakarta. Jurnal Penelitian Humaniora (online), 154-169.

Nurohman, S. 2013. Pendekatan Project Based Learning sebagai Upaya Internalisasi Scientific Method bagi Mahasiswa Calon Guru Fisika. Jurnal Pendidikan Matematika Dan Sains 1 (2) UNY, 158-164.

Shor, I. d. 2001. Menjadi Guru Merdeka (Penerj: A. Nashir Budiman). Jogjakarta: LKiS. Snyder, J. 2000. From Voting to Violence: Democratization and Nationalist Conflict. New York, London: W.W. Norton \& Company.

Stewart, F. 2002. Horizontal Inequalities: A neglected Dimension. Queen Elizabeth House: Oxford.

Tilaar, H. 2012. Kaleidoskop Pendidikan Nasional. Jakarta: Penerbit Buku Kompas. 